\title{
Use of the MOOC for a Change of Attitude Towards Science and its Teaching
}

\author{
Rajaa Aoulad Moussa, Mourad Madrane, Rachid Janati-Idrissi, Mohammed Laafou \\ Interdisciplinary laboratory of Research in Pedagogic Engineering, ENS-Tétouan, Morocco \\ rajoua78@yahoo.fr
}

\begin{abstract}
This work describes conceptual changes in science and its teaching; Observed among 200 primary school teachers after the application of a didactic proposal (on-line training).

We used a platform as training and learning space to apply the didactic proposal.

Attitudes were assessed by means of an instrument, applied before and after the proposal. The instrument included the three traditional components of attitude (cognitive, affective and active) across different scales, semantic differential and forced option reagents. The results of the preliminary survey, carried out before the didactic intervention, revealed that primary school teachers have notions, emotions and actions, which translate into unfavorable attitudes towards natural sciences, which directly affect their teaching practice.
\end{abstract}

After the application of online training, it was obvious both qualitatively and quantitatively a positive change in the attitudes of teachers towards science and its teaching.

Keywords- platform, science; Change of attitude; Science teachers; online training; primary education

\section{Introduction}

One of the missions of the teaching of sciences is to make it possible to the future citizen to acquire a minimum of scientific culture. However as shown by the results of several studies and investigations (PNEA 2008) [1] and (TIMSS 2003, 2007, 2011) this task appears difficult. A concern is raised in Morocco following the disaffection of the course of scientific training. It is related to the fear of lacking scientific executives to ensure the economic development of the country and citizens equipped with a basic scientific culture, as well as to the will to improve the situation in this field. These concerns do not go back to today since they appear already in the speeches of the scientists of the Twenties and in the reports of research by 1948 [2].

The research results in connection with the attitudes of the pupils towards sciences show that they constitute a good predictor of the intention to engage in scientific studies, alone [3], or associated with other elements relating to social environment or to personal experience[4].

In this research, we will focus on the attitudes, because of their close and undeniable relationship with the teaching of sciences. For several years, it has been recognized that the emotional variables are as important as the cognitive variables to influence the training. The emotional variables are regarded as 
important not only for their influence on the use, but because they are themselves the very relevant results of training [5].

For this reason the goal of this study was to guide a favorable change of attitude towards sciences and their teaching among primary school teachers by an educational proposal based on creative and entertaining activities.

In this study, we suggest an alternative solution to cure these problems through the development of a teacher training using an e-learning platform, which would be much more advantageous than the one we would provide within the framework of classroom training [6]. The reasons that justify this choice are of economic and didactic order. Compared to this last point, such teaching would make it possible for each teacher to learn from his knowledge of the subject of study, which is difficult, not to say impossible, in classroom teaching. [7].

\section{Foundation and Development of On-line Training}

One of the main problems of the teaching of sciences in Morocco is the difficulty which the teachers have to conceive of the strategies of suitable teaching to help their pupils develop a positive attitude towards science and as results they adapt the scientific knowledge.

The conceptions of the pupils and the teachers regarding science were the object of many works[8][9][10][11] These attitudes, analyzed in relation to epistemological references, are in most cases incoherent, kinds of several epistemological models, around an identified reason as holding mainly of a model which sends back to empiricism as to the status of knowledge, to realism as to their relation with the objects they talk about, to positivism as to the existence of a standard and a-historical approach to ensure its validity and to induction as regards the development process.

A research Moroccan provided by A.Moussa\& al presented to the CIMQUSEF12 in 2016, shows that the majority of the primary school teachers adopt unfavorable attitudes regarding science, because of, among other things, the lack of mastery of the scientific contents and the lack of knowledge about practical and experimental activities [12].

According to Duit and Treagust, in order to go beyond this more traditional teaching, the conceptual change can be a research track"Research has shown that conceptual change informed teaching usually is superior to more traditional means of teaching. Hence, conceptual change may still be a powerful frame for improving science teachingand learning."[13]

Primary school teachers must thus deeply know the scientific contents, which they teach, recognize their attitudes, recognize how to teach sciences and develop aptitudes and necessary competences to promote the positive attitudes among their pupils. This leaves the teachers in front of the challenge to face their own practice in order to try to transform their teaching strategies, an extremely difficult task, because of other factors, the lack of an initial adequate training[13].

An e-learning was conceived the goal of which is to direct a positive change of attitude towards sciences and its teaching. The training is founded on a theoretical and methodological reflection on the approach of traditional teaching practiced in the majority of primary school classrooms, to try to transform it into a constructive process where teachers can exert their creativity and where pupils build their scientific knowledge in an interesting and amusing way[6]. 
Rajaa Aoulad Moussa, Mourad Madrane, Rachid Janati-Idrissi, Mohammed Laafou. Use of the MOOC for a Change

of Attitude Towards Science and its Teaching. Transactions on Machine Learning and Artificial Intelligence,

Vol 5 No 4 August (2017); p: 488-498

For the development of this training we took account of the orientations to elaborate international strategies and programs, in which the value of nature are recognized; facilitates the interaction between elements of primary education program and the community; includes practical activities which facilitate the conception of science as a dynamic process and in construction related to reality; presentation of the contents as unfinished and significant for the students and to develop a critical and reflexive awareness. These global directives are founded, from a constructivist point of view, in which the attitudes of the teachers and the pupils play a very important part in the training process [14].

Moreover, from this constructivist perspective, to explain the strategies used in the teaching of natural sciences, it is necessary to define first the conditions of the subject, the learning process, the contents and the objectives, the teaching equipment, the of evaluation ends and the role of the teacher.

The subject covered in this training was that of "nutrition" it is part of the official curriculum of Moroccan primary education. We consider it important to propose this subject for some reasons. Firstly, the importance for the children to acquire the fundamental knowledge to understand the natural phenomena, mainly those in relation with health preservation. Secondly, the importance of an adequate nutrition. It is present along the six degrees of primary education and thirdly, because it is a subject which teachers fail to present in an interesting way to their pupils[1].

The activities were designed as cognitive, emotional and active strategies to direct teachers to a positive change of attitude towards sciences and at the same time to help them understand in a profound and amusing way the contents that they will learn. The didactic approach was realized through activities that tried to facilitate, for the teachers, the management and the teaching of some contents on nutrition, in a way that they were translated into significant learning for the pupils. Through this e-learning teachers were expected to:

a) Be able to link the science contents to the daily reality their pupils.

b) Acquire the didactic component of scientific contents.

c) Promote their creativity to develop didactic strategies feasible and realizable in class.

d) Encourage the development of competences that support a skill so much in the teaching of science as in other subjects.

\section{Reason and Advantage of The Use Of Mooc For The Application of Teacher Training}

During their initial training, primary education teachers acquire a vast knowledge which is characterized by what is called "knowing the subject to be taught". Learning these contents is a requirement although nonsufficient, i.e. it does not guarantee an automatic transfer to the classroom practice in [15][12].

To correct the gaps in the initial primary education teachers' training, it is necessary to provide them with didactic materials that make it possible to work, in class, with the learned contents concerning the nature of science and that enable them to integrate in a single structure varied knowledge from the subject to be taught

The national Charter of education and training stipulates that any teacher has to profit obligatorily from a 30 hours training a year, and it is only in the 2009-2010 school year that this principle was applied for the first time to all primary education teachers ( 5 days of training at a rate of 6 hours a day on the 
competence-based approach and the pedagogy of integration) [7]. The application of this principle raised other issues relating to the trainers' qualification, the material conditions of the training occurrence and the securing of the pupils' school time during the teachers' absence due to the training.

From this point of view, the development of a model of distance training would be much more advantageous than that which could be provided within the framework of a classroomtraining [6]. The reasons which justify this choice are of economic and didactic nature. Compared to this last point, such training would make it possible for each teacher to learn how to start from his knowledge on the subject of study, which is difficult, not to say impossible, in a classroom training [7].

\subsection{Choice of platform}

There exists a variety of e-Learning platforms - which diffuse massive, open and free online courses (MOOC) - available on the Web [16]. Each one of them has different characteristics that make it flexible to adapt to various training contexts. The choice of eFront learning platform was taken for the following reasons [17]:

- It is a complete and effective platform.

- It is easy to use

- It is free software: One can personalize it according to the needs for the training and the learners.

- It is compatible with several operating systems

- It is of last generation.

- It is an intelligent platform: The trainers can set access rules to the resources (obligation to read, to get certain results $\cdots)$. The trainer can thus easily define a teaching plan of training.

\subsection{Choice of the training mode}

According to Walkiers and Praetere, the collaborative training is any learning activity carried out by a group of learners having a common goal, being, each of them, a source of information, of motivation, of interaction, and of mutual aid and profiting from each other's contributions, of the group synergy and the assistance of a trainer facilitating individual and collective leanings.[18]

The online collaborative training encourages reflection, resource sharing, autonomy, the critical spirit and of synthesis. It is a method in agreement with the proposals of this training, since it is based on the following concepts:

- $\quad$ The communicational aspect of TIC can support a collaborative work by offering tools of communication, of creation and access to a large variety of resources [17]

- $\quad$ The subject of knowledge is autonomous;

- $\quad$ Cooperation constitutes the fundamental activity for expansion, knowledge structuring and resolution of identified problems;

Our distance training is based on an online training platform that offers the teachers the opportunity to publish their learners' cognitive problems and to try to analyze them by exploiting the various communications tools of the platform used. 
Rajaa Aoulad Moussa, Mourad Madrane, Rachid Janati-Idrissi, Mohammed Laafou. Use of the MOOC for a Change

of Attitude Towards Science and its Teaching. Transactions on Machine Learning and Artificial Intelligence,

Vol 5 No 4 August (2017); p: 488-498

The intention of the collaborative online training is to encourage an active training and to develop cooperative work among teachers.

\section{Methodology}

We are interested in comparing the teachers' attitudes before and after being subjected to a didactic proposal online. Participants were not randomly selected; the accent of research was quasi-experimental, by means of a questionnaire, applied before and after the proposal (pre-test - post-test). The instrument included the three traditional components of the attitude: cognitive, emotional and active through various Likert scales: semantic differential and reactive of forced option [19].

\subsection{Sample}

A sample of 200 teachers working at the public primary schools, of the provincial direction of national education and of vocational training of Tétouan.

These teachers have an average seniority of approximately 14 years. $65 \%$ are women. All participants have had an initial training in teachers training centers but the duration of their training varies. $68 \%$ had only one year training while others had two years.

\subsection{Questionnaire in connection with the attitudes}

To evaluate the possible changes in the attitudes of the teachers, a questionnaire was provided to them on the attitudes related to science before and after the proposal, which includes the three traditional components of attitude (cognitive, emotional trend and active) by Likert's scales, semantic differential and reactive forced choice. This instrument is composed of several parts: the first part comprises teachers' biographical and university data (age, sex, years of experience and the number of students). The second part includes questions about their attitudes in regards science, its teaching and about the scientific and experimental activities (emotional component). Thanks to semantic differential scales; in the third section teachers were questioned on their knowledge and beliefs related to sciences, their teaching, the scientific research and the characteristics of scientists (cognitive component). In the fourth section, the questions related to the activities of scientific research (component cognitive). In the fifth part, the questions were about teachers' preferences concerning science activities (component of trend). The last part was about opinions in connection with science and the scientific and technological research.

\subsection{Procedures of analysis}

The obtained results were organized and classified in categories to analyze them. For profound sessions we carried out a general qualitative analysis of the contents of information provided by the teachers, by establishing categories and units of analysis. Categories: a) topic, referring to the covered issues like science and the production of scientific knowledge, its relationship to technology; a teaching and a learning of science and an improvement of teaching strategies. - b) direction, relative to the issue which was covered, in a favorable or unfavorable way and c) value, relative to the importance the teachers granted the covered issue. Units of analysis, being 1) words, science, technology, didactics, contents between the others - and 2) the subject, science and its teaching. 
The data of the pre-test and post-test were analyzed in a global way by obtaining the descriptive statistics - an average, a standard maximal and minimal error of the average, of values - and the answer percentages, with an objective to describe teachers' changes and trends of attitudes .

We applied Statistical Package for the Social Sciences, SPSS version 12 in order to see whether there were significant differences between the pre-test and the post test, taking into account the size of the effect observed, statistical on that which carries out the interpretation of the size of the observed differences. In other words, between the teachers' attitudes before and after the proposal; the values and the averages of greater value indicated a positive or favorable direction of attitudes and the averages of less value a negative or unfavorable direction of attitudes.

\section{Results and Discussion}

\subsection{Teachers' comments and opinions related to sciences}

In the first part of the training, by means of depth sessions, evoked teachers' reflection and discussion through detailed questions in order to know the comments and opinions of the primary school teachers participating in this study related to science.

Questions 1 and 2 were conceived with an aim to make teachers explain the role that science plays in our society and what are, in their opinions, its objectives and characteristics.

The majority of answers (66.67\%) affirm that science tries to give answers to the phenomena or the problems of nature. Only $16.5 \%$ explicitly mentioned the social context where the scientific activity is developed and only $16.66 \%$ underlined the specific character of scientific methodology. But, the important aspects of epistemology of contemporary science like creativity, imagination or personal subjectivity and the influence of research programs on the work of the scientists were mentioned by no teacher.

As for the characteristics and the objectives of science, they stress that the scientific knowledge is obtained by means of empirical evidence (50\%) allot it values such as "objectivity" and "exactitude".

It should be stressed that almost $33.3 \%$ of the answers present unrelated and indecipherable explanations. This is why we can as well conclude that there exists a preliminary lack of reflection on the objectives of science and its social function.

Questions 3 and 4 were conceived so that the students explain the role of the experiment in the scientific activity. Question 3 is a direct one that aims at extracting their definitions of the characteristics of an experiment and question 4 interrogates them on the role that experiments play in the development of a scientific research.

$66.67 \%$ of the teachers define the experiment as a try to empirically check a declaration or a theory, although they do not specify how the theory to check appeared. More than a third of the answers explicitly state that it is necessary firstly to develop the assumptions, which will subsequently be contrasted by means of experiments. In no case they include the definition of experiment nor explicitly state that it is part of a more total and complex research. However, practically all the students consider that the scientific knowledge needs experiments to be developed.

In coherence with the previous results, a large number of explanations justifies the importance of experiment as empirical verification of theories, not indicating any other rate of validation of these, its 
Rajaa Aoulad Moussa, Mourad Madrane, Rachid Janati-Idrissi, Mohammed Laafou. Use of the MOOC for a Change

of Attitude Towards Science and its Teaching. Transactions on Machine Learning and Artificial Intelligence,

Vol 5 No 4 August (2017); p: 488-498

predictability, universality and coherence with the theoretical framework. A third of the respondents considers that starting from experimentation we produce explanations or theories, in a clear empiricalinductive conception of science.

The purpose of questions 5 and 6 is to examine what teachers think of the role of theories in scientific knowledge. Question 5 is a direct one about the reliability of scientific theories and question 6 wonders about the difference between empirical evidence and explanatory theories.

With regard to what teachers think of the role that theories play in scientific knowledge, we notice that almost $66.67 \%$ confer a very high degree of certainty to theories, while only $16.66 \%$ indicate an average certainty and nobody allots them a low degree of certainty. However, practically all the justifications with this high degree of confidence to the scientific theory refer to the experiments they use to demonstrate it, as well as to the current technological devices. In the explanations, the difference between the experimental facts and the theoretical concepts conceived to explain them is not mentioned.

These results confirm the preliminary investigations which they report that an empiricist designs in connection with sciences still prevail among teachers, and in which the scientific knowledge is regarded as isolated truths and the training of those must be invariable [20]. On the production of the scientific knowledge. A good part of them (75\%), mentioned that this kind of knowledge was generated in a laboratory while following each step of the scientific method, therefore. It is important on the one hand, to get rid of the idea saying that the production of scientific knowledge only happens and exists in the laboratory (Fourez, 1992). On the other hand, to eradicate this rigid vision they have with regard to the scientific method, which is considered a series of steps or of stages that must be followed in strict order and in a mechanical way. This is why, a teaching training is very important; that which includes an adequate comprehension of the nature of scientific knowledge (Abd-El-Khalick and Lederman 2000).

\subsection{Attitudes towards biology and teaching}

In the second part of the proposal, we worked with primary school teachers on the subject of "nutrition" through cheerful activities. Generally, the results showed favorable changes of attitude. The tables which are presented then show the results by component of attitude, obtained in the pre-test and post-test of various scales included in the instrument applied.

With regard to the emotional component of the attitude, tables 2 and 3 show descriptive statistics of the emotions expressed by the teachers towards science and its teaching obtained in the pre-test and posttest of the total items of the semantic differential referring to the emotions that science (table 1) and its teaching (table 2) produce among the questioned teachers.

Table 1: Descriptive Statistics of the Feelings which Sciences Produce in the Primary's Schools Teachers.

\begin{tabular}{|c|c|c|c|c|c|c|}
\hline & Average & NR & $\begin{array}{c}\text { Deviation } \\
\text { Standard }\end{array}$ & $\begin{array}{c}\text { Error } \\
\text { Standard }\end{array}$ & Min & Max \\
\hline Pre-test & 482.7155 & 200 & 7.80816 & 1.84040 & 25 & 54 \\
\hline Post test & 773.4555 & 200 & 3.97254 & .93634 & 39 & 56 \\
\hline
\end{tabular}


Table 2: Descriptive Statistics of the Feelings which Science Produces among Primary School Teachers

\begin{tabular}{|c|c|c|c|l|c|c|}
\hline & Average & NR & $\begin{array}{c}\text { Deviation } \\
\text { Standard }\end{array}$ & $\begin{array}{c}\text { Error } \\
\text { Standard }\end{array}$ & Mini & Maxi \\
\hline Pre-test & 570.9877 & 200 & 9.6779 & 2.2811 & 35 & 67 \\
\hline Post test & 721.6044 & 200 & 3.0190 & .7115 & 60 & 70 \\
\hline
\end{tabular}

In these tables we notice that the averages of the post-test in these scales of attitude were larger than those of the pre-test. The average trend of emotions in the pre-test proved unfavorable, while in the posttest it tended to be very favorable.

With regard to the beliefs and the knowledge expressed by the teachers - of this cognitive samplecomponent of the attitude- in table 6 we shows the descriptive statistics obtained in pre-test and posttest through a standard scale Likert type. In this table, we notice an increase in the total average in posttest, which indicates a trend of change in the beliefs after the application of the proposal.

Table 10: Descriptive Statistics of the Beliefs and Knowledge in Keeping with Science and its Teaching Among Primary School Teachers.

\begin{tabular}{|l|c|c|c|c|c|c|}
\hline & Average & NR & Deviation & Error & Min & Max \\
\hline Pré-test & 641.3577 & 200 & 6.26668 & 1.47707 & 41 & 74 \\
\hline Post test & 735.8022 & 200 & 3.67112 & .86529 & 61 & 67 \\
\hline
\end{tabular}

To obtain information on the active component or of the trend to action of the attitude, we asked teachers to express their preference to succeed in certain activities in relation and without relation with science. The results are shown in tables 4 and 5.

Table 11: Descriptive Statistics of Teachers' Preferences for Science-Related Activities before and After Training.

\begin{tabular}{|l|c|c|c|c|c|c|}
\hline & Average & NR & $\begin{array}{c}\text { Deviation } \\
\text { Standard }\end{array}$ & $\begin{array}{c}\text { Error } \\
\text { Standard }\end{array}$ & Min & Max \\
\hline Pre-test & 91.3577 & 200 & 4.03741 & .95163 & 0 & 14 \\
\hline Post test & 124.6911 & 200 & 3.11648 & .73456 & 5.00 & 15 \\
\hline
\end{tabular}

The data of table 4 shows an increase of the average in post-test. This means that teachers expressed a greater preference to bring to succeed in activities related to science after the application of the didactic proposal.

In table 5 we notice the test results of $t$ testing and the size of the effect with regard to the active component. The change in the average of the post-test is significant with a $p<0.01$ and the size of the effect proved to be greater than one. 
Rajaa Aoulad Moussa, Mourad Madrane, Rachid Janati-Idrissi, Mohammed Laafou. Use of the MOOC for a Change

of Attitude Towards Science and its Teaching. Transactions on Machine Learning and Artificial Intelligence, Vol 5 No 4 August (2017); p: 488-498

Table 12: Changes in the Preferences of Primary School Teachers (*Significant At P <0.01).

\begin{tabular}{|l|l|l|l|c|c|c|}
\hline & Average & Average & Size & Error & & \\
\hline $\begin{array}{l}\text { Preferences for : } \\
\text { related to science }\end{array}$ & Per-test & Post-test & effect & standard & $\mathrm{t}$ & Sig \\
\hline
\end{tabular}

The fact that teachers expressed, before the implementation of the training, their preference to carry out non-scientific activities could be due to the difficulty in understanding and explaining the scientific knowledge and to the lack of clarity of scientific activities (Seam, 2002). After having applied the activities of the e-learning, teachers expressed a greater preference for the realization of science-related activities. We also noticed, on the part of the participating teachers, more enthusiasm, which enables us to suggest, on the basis applied by Perkes[21] - teachers who feel well prepared and who have self-confidence teach science better - that they have become more self-confident to carry out simple practical activities and to teach the contents of scientific programs.

By analyzing the three components of the attitude, we find that the attitudes of the teachers of this study were unfavorable towards science - as they shown by the results of the pre-test of the three components of the attitude. When teachers had taken part in the training, they showed significant changes and they showed us a more favorable attitude towards science and its teaching. The analysis of the results makes it possible to consolidate the assertion that to develop good school science and to get to significant knowledge one requires a positive attitude, an interest and a will.

After the application of the e-learning, we notice among the teachers a greater openness, a greater selfconfidence. However, it is important to admit that the teachers constantly tried to provide their pupils with significant teaching and reflective thought but they do not always succeed. For that, we want to explain that with this proposal we try to direct only a favorable change of attitude and through that, to provide the teacher, in the simplest way, with some elements that help him in his task as a facilitator of learning.

\section{Conclusions}

The obtained results of this study show that primary school teachers are very motivated to profit from training. The suggested solution is based on the distance training that gives a very great flexibility to the teachers on the level of time and space.

The results also showed a favorable change of attitude towards science and its teaching. It is important to mention that for this change to be permanent we have to continue to innovate and to provide teachers with a continuous training.

This study showed that it is possible to change negative attitudes into positive attitudes towards science and its teaching, by means of a didactic proposal based on a reflection on the teaching practices in class. However, it is important to mention that this training was applied in a short time to a population of 200 teachers belonging to only one delegation. This is why it has to be taken into account that it is not possible to generalize these results. The data obtained from this research reveal that teachers need to be provided with strategies in order to help them to better direct the construction of knowledge among their pupils. 
The results of this study enable us to suggest that to obtain a positive change of attitude towards sciences and its teaching, it is necessary firstly that the teachers become aware of their own attitudes and thus, will subsequently be able to develop favorable attitudes through self-confidence and reflection on their own teaching practices.

In addition, the results of this research revealed important educational implications. It is suggested that besides laying out positive attitudes towards sciences the professors:

b) Show to their pupils the utility of scientific knowledge so that they are interested in science and get to a significant learning.

c) Integrated to other continuous online training programs to be able to develop their innovating strategies of teaching-learning of sciences.

d) Take into account the social and environmental context to build significant processes of teachinglearning.

Finally, in this research we consider that if we are interested in the development of a high quality teaching of science at the primary school, then we must start with a change of attitude.

\section{REFERENCES}

[1] Superior Council of Education, "Analytical Report," MOROCCO, 2009.

[2] J BENNET, "The development and use of an instrument to assess students' attitude to study of chemistry," International Journal of Science Education, pp. 833-845, 2001.

[3] Noman REID and Elena A SKYABINA, "Attitudes towards Physics," Research in Science \& Technological Education, vol. 20, pp. 67-81, 2002.

[4] Frank E CRAWLEY and Annette E COE, "Determinants ofmiddle school students' intention to enrol in a high school science : an application of the theory of reasoned action," Journal of research in science teaching, vol. 27, pp. 461- 476, 1990.

[5] Thomas R Koballa, "Attitude and relatedconcepts in science education," Science Education, vol. 72, no. 2, pp. 115-126, 1988.

[6] Abdeljalil Métioui and Louis Trudel. (2009) Revue permanente en ligne des utilisateurs des technologies de l'information et de la communication. [Online]. HYPERLINK "http://isdm.univtIn.fr/PDF/isdm39/Article_Isdm_Ticemed09_Metioui_Trudel_PhB\%20ok.pdf" http://isdm.univthn.fr/PDF/isdm39/Article_Isdm_Ticemed09_Metioui_Trudel_PhB\%20ok.pdf

[7] Fouad Chafiqi and A Alagui, "Réforme éducative au Maroc et refonte des curricula dans les disciplines scientifiques," Carrefours de l'éducation, pp. 29-50, 2011.

[8] ABD-EL-KHALIC, F.; LEDERMAN, N.G, "Improving science teachers' conceptions of the nature of science: A critical review of the literature," International Journal of Science Education 22, pp. 665-701, 2000.

[9] Jacques Desautels and Marie Larochelle, Autour de l'idée de science.: De Boeck-Wesmael, 1992. 
Rajaa Aoulad Moussa, Mourad Madrane, Rachid Janati-Idrissi, Mohammed Laafou. Use of the MOOC for a Change

of Attitude Towards Science and its Teaching. Transactions on Machine Learning and Artificial Intelligence,

Vol 5 No 4 August (2017); p: 488-498

[10] ARIZA R PORLAN , GARCIA E GARCIA, and GARCIA RIVERO, "Porlan Ariza, P., \& al. (1998).Les obstacles à la formation professionnelle des professeurs en rapport avec leurs idées sur la science, l'enseignement et l'apprentissage," Aster, pp. 207-235, 1998.

[11] Ezio Roletto, "La science et les connaissances scientifiques," Aste, no. 26, pp. 11-30, 1998.

[12] Rajaa AOULAD MOUSSA, Mourad MADRANE, Rachid JANNATI-IDRISSI, and Mouhamed LAAFOU, ENJEUX DE LA FORMATION INITIALE DES FUTURS ENSEIGNANTS DES SCIENCES AU PRIMAIRE, Avril 8-9, 2016. "unpublished"

[13] Duit Reinders and David F Treagust, "Conceptual change: A powerful framework for improving science teaching and learning," International Journal of Science Education, vol. 25, no. 6, pp. 671-688, 2003.

[14] Commission Européenne EUR22845, "- L'enseignement scientifique aujourd'hui: une pédagogie renouvelée pour l'avenir de l'Europe Luxembourg," Office des publications officielles des Communautés européennes, 2007.

[15] D. HODSON, "In search of a meaninful relationship: an exploration of some issues relating to integration in science and science education," International Journal of Science education, pp. 541-562, 1992.

[16] Melody M Tsang, Ho Shu-Chun, and Liang Ting-Peng, "Consumer Attitudes Toward Mobile Advertising:An Empirical Study," International Journal of Electronic Commerce, vol. 8, no. 3, pp. 65-78, 2004.

[17] Mohamed Chekour, Mohaamed Al Achhab, and Mohamed Laafou, "Integration of Blended Learning in Teaching Computer Science in Moroccan High Schools," International Journal of Computer Technology and, vol. 4, no. 6, 2013.

[18] Marc Walckiers and Thomas De Praetere, "L'apprentissage collaboratif en ligne, huit avantages qui en font un must. Distances et savoirs," vol. 2, no. 1, pp. 53-75, 2004.

[19] J BENNETT, "Science with attitude: the perennial problem of pupils' responses to science," School Science Review, pp. 59-70, 2001.

[20] Jacques Desautels and Marie Larochelle, "Qu'est-ce que le savoir scientifique?," de la Pensée Éducative, pp. 96-98, 1993.

[21] "Relationships between a teacher's background and sensed adequacy to teach elementary science," Journal of Research in Science Teaching, vol. 12, pp. 85-88, 1975.

[22] Sébastien George, Gaëlle Molinari, Chihab Cherkaou, "Le réseau social Face-book comme support d'apprentissage pour les étudiants universitaires.," in 7ème Conférence sur les Environnements Informatiques pour l'Apprentissage Humain, Agadir, 2015, pp. 102-113.

[23] LAROCHELLE M.in collaboration with PÉPIN Y DÉSAUTELS J., "Étude de la pertinence et de la viabilité d'une stratégie de formation à l'enseignement des sciences. ," Ottawa, 1994. 